06

\title{
Газофазная эпитаксия слоев AIN на темплейте AIN/Si(111), синтезированном методом реактивного магнетронного распыления
}

\author{
(c) В.Н. Бессолов ${ }^{1}$, Н.Д. Грузинов ${ }^{2}$, М.Е. Компан ${ }^{1}$, Е.В. Коненкова ${ }^{1}$, В.Н. Пантелеев ${ }^{1}$, С.Н. Родин ${ }^{1}$, \\ М.П. Щеглов 1 \\ ${ }^{1}$ Физико-технический институт им. А.Ф. Иофффе РАН, Санкт-Петербург, Россия \\ ${ }^{2}$ Санкт-Петербургский национальный исследовательский Академический университет им. Ж.И. Алфёрова, \\ Санкт-Петербург, Россия \\ E-mail: bes@triat.ioffe.rssi.ru
}

Поступило в Редакцию 22 января 2020 г.

В окончательной редакции 22 января 2020г.

Принято к публикации 27 января 2020г.

\begin{abstract}
Эпитаксиальные слои $\mathrm{AlN}$ выращены на подложке $\mathrm{Si}(111)$ при последовательном применении нескольких методов: реактивного магнетронного распыления (до толщины $20 \mathrm{~nm}$ ), газофазной эпитаксии из металлоорганических соединений (до толщины $450 \mathrm{~nm}$ ) и хлоридно-гидридной газофазной эпитаксии (до толщины $2 \mu \mathrm{m}$ ). Формирование AIN таким комбинированным методом обеспечивает существенное снижение деформации слоя и подавление формирования трещин.
\end{abstract}

Ключевые слова: нитрид алюминия, кремний, газофазная эпитаксия.

DOI: 10.21883/PJTF.2020.08.49305.18215

Нитрид алюминия (AlN) представляет собой широкозонный полупроводник и обладает рядом ценных свойств: он перспективен для применения в ультрафиолетовой фотонике и благодаря своим пьезоэлектрическим свойствам может использоваться в высокочастотных поверхностно-акустических устройствах. Кроме того, он используется в качестве буферного слоя для эпитаксии III-нитридных полупроводников на чужеродных подложках, таких как сапфир, $\mathrm{SiC}$ и $\mathrm{Si}$. Возможность использования подложки $\mathrm{Si}(111)$ открывает дополнительные возможности благодаря большим размерам кремниевых подложек и их низкой стоимости. Также тонкий слой AlN не препятствует вертикальной проводимости носителей заряда путем туннелирования [1], поэтому использование AlN для структур с вертикальным протеканием носителей заряда является предпочтительным направлением для приборов нитрид-галлиевой электроники на кремнии.

Известны попытки выращивания слоев AlN на подложке $\mathrm{Si}(111)$ различными методами: газофазной эпитаксии из металлоорганических соединений (MOCVD) [2], хлоридно-гидридной газофазной эпитаксии (HVPE) [3], молекулярно-пучковой эпитаксии (MBE) [4]. Однако эпитаксиальный рост слоя $\mathrm{AlN}$ на $\mathrm{Si}$ затруднен из-за большого различия постоянных решеток $\mathrm{AlN}$ и $\mathrm{Si}$ ( 19\%) [5]. Кроме того, значительно различаются коэффициенты термического расширения этих материалов $\left(\Delta \alpha=\alpha_{\mathrm{AlN}}-\alpha_{\mathrm{Si}}=4.5 \cdot 10^{-6}-3.8 \cdot 10^{-6} \mathrm{~K}\right)[6]$. Это приводит к высоким механическим напряжениям и растрескиванию слоев с увеличением их толщины; согласно [7], слои сильно подвержены растрескиванию уже при толщинах $300 \mathrm{~nm}$.
Подобная проблема существует и при выращивании $\mathrm{GaN}$ на $\mathrm{Si}(111)$ с буферным слоем AlN. B работе [8] была использована имплантация ионов азота через буферный слой $\mathrm{AlN}$, нанесенный на подложку $\mathrm{Si}(111)$. Была достигнута частичная структурная разориентация в буферном слое $\mathrm{AlN}$, а также частичное снятие напряжений в слое $\mathrm{GaN}$. Недавно для снятия напряжений в слоях AlN обсуждалась возможность применения магнетронного распыления [9]. Это простой технологический прием, при котором температура синтеза может быть понижена, что должно привести к уменьшению постростовых деформаций. Кроме того, ожидается, что низкая температура роста может дать значительное преимущество для предотвращения интердиффузии между $\mathrm{Si}$ и $\mathrm{Al}[10]$.

В настоящей работе предложен новый подход, а именно: тонкий слой $\mathrm{AlN}$ синтезировался на $\mathrm{Si}(111)$ по технологии реактивного магнетронного распыления (RMS), а два последующих слоя AlN - методами MOCVD и HVPE. Для оценки эффективности метода были синтезированы два типа структур AlN на подложке $\mathrm{Si}(111)$ - тип $A$ (предварительно наносился слой $\mathrm{AlN}$ толщиной $20 \mathrm{~nm}$ методом RMS) и тип $B$ (без нанесения слоя) - и затем последовательно синтезировались два слоя AlN методами MOCVD и HVPE (рис. 1). Процесс нанесения слоя AlN методом RMS проходил в плазменной смеси $\mathrm{N}_{2} / \mathrm{Ar}$ при $T=450^{\circ} \mathrm{C}$. Слои $\mathrm{AlN}$ толщиной $450 \mathrm{~nm}$ на обоих типах структур были выращены методом MOCVD на модифицированной установке EpiQuip c горизонтальным реактором и индукционно нагреваемым графитовым подложкодержателем аналогично [11]. Затем структуры охлаждались до комнатной температуры и перемещались в реактор для выращивания AlN тол- 


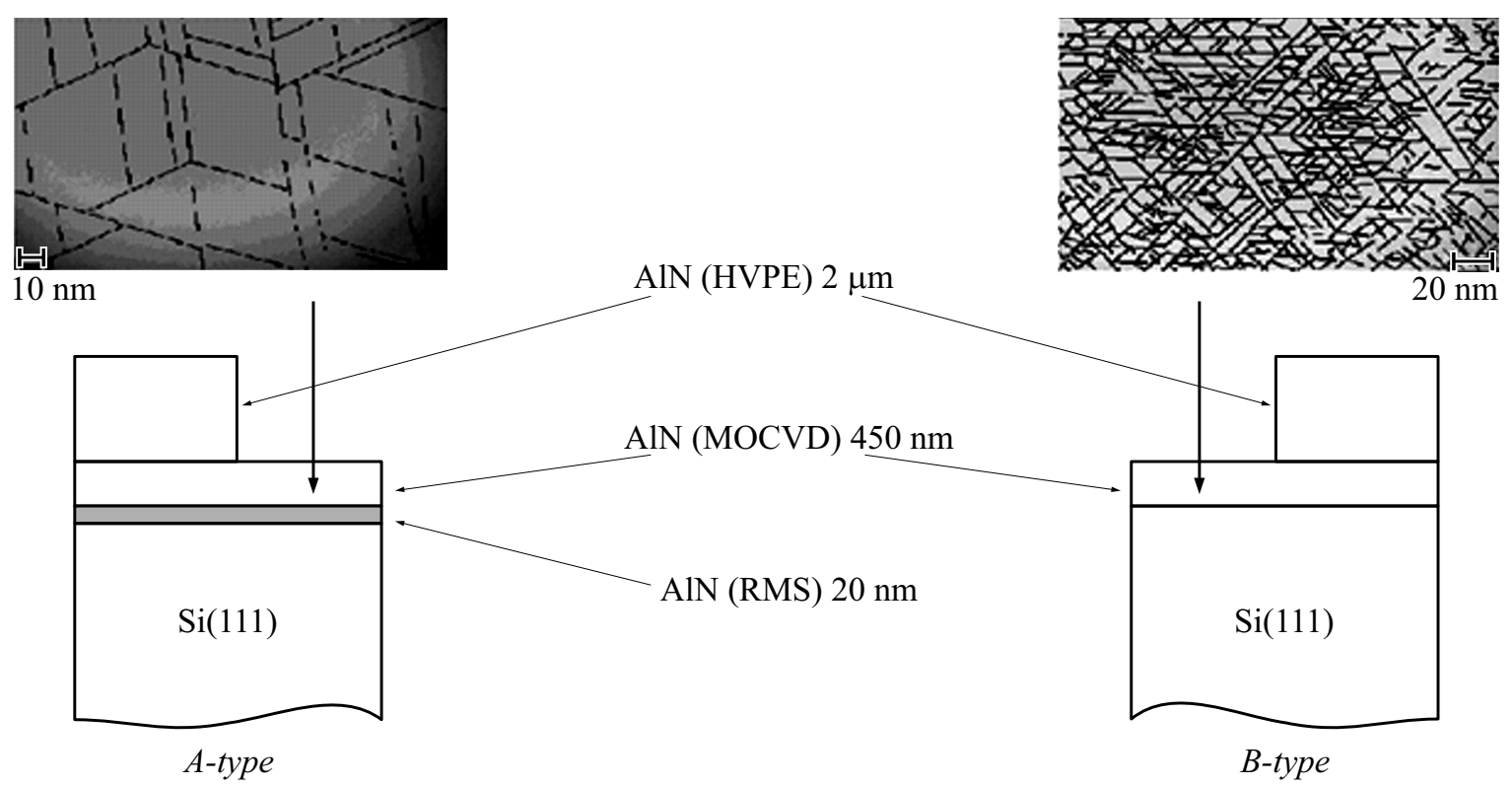

Рис. 1. Структура образцов типов $A$ и $B$ и оптическое изображение трещин на поверхности слоев при соответствующем методе выращивания.

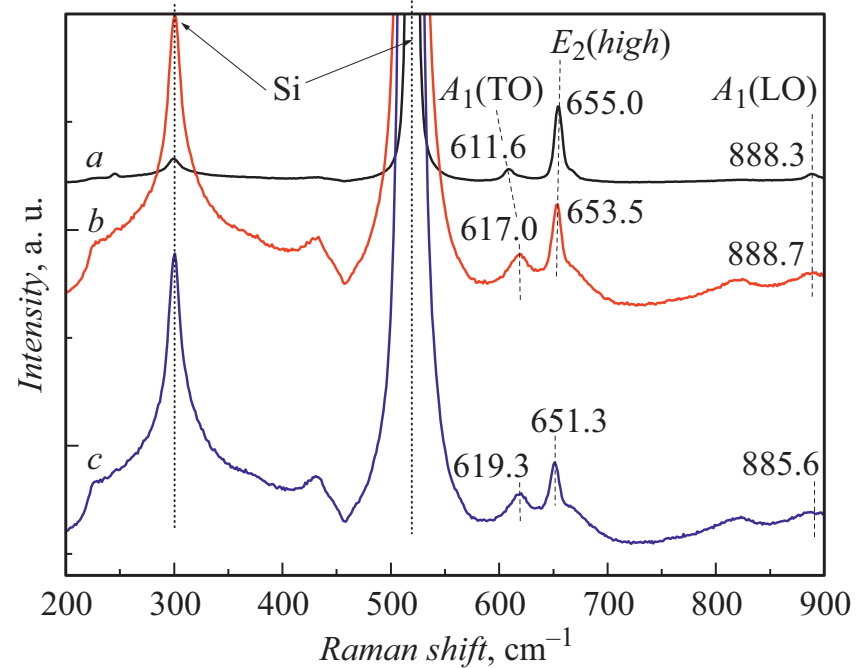

Рис. 2. Спектры КРС структур $\operatorname{AlN} / \operatorname{Si}(111) . a-$ тип $A, b-$ тип $B, c-$ после синтеза слоя методом MOCVD.

щиной $2 \mu$ т методом HVPE аналогично [3]. Выращенные образцы исследовались методами рентгеновской дифрактометрии, оптической микроскопии, комбинационного рассеяния света (КРС).

При рентгеноструктурных измерениях кривые качания регистрировались в режиме двухкристальной схемы дифракции ( $\omega_{2 \theta}$-мода) аналогично [3]. Комбинационное рассеяние света осуществлялось с помощью рамановского спектрометра JY HORIBA MRS 320. Источником света был гелий-неоновый лазер с длиной волны излучения $632.8 \mathrm{~nm}$. Исследования проводились при комнатной температуре аналогично [12].
Результаты экспериментального исследования полученных слоев AlN были следующими.

Рентгенодифракционный анализ показал, что слой $\mathrm{AlN}(0002)$, синтезированный методом RMS на подложке $\mathrm{Si}(111)$, имеет текстурный характер с полушириной кривой качания рентгеновской дифракции (FWHM) несколько градусов, слои $\operatorname{AlN}(0002)$ структур типа $A$ и $B$, синтезированные методом MOCVD, имели FWHM $\omega_{\theta}=35$ и $60 \operatorname{arcmin}$ соответственно, а после синтеза AlN методом HVPE FWHM $\omega_{\theta}$ имела величины 40 и 65 arcmin соответственно.

Оптические изображения поверхности AlN после синтеза методом MOCVD слоя толщиной $450 \mathrm{~nm}$ выявили наличие систем трещин разной плотности: размеры блоков AlN у структуры типа $A$ в несколько раз крупнее, чем для типа $B$ (рис. 1).

Поскольку точки зарождения трещин случайны и система трещин нерегулярна, для объективного анализа видимой картины было применено фурье-преобразование, которое позволило определить средний размер цельного блока (средний латеральный период трещин). Этот анализ показал, что размер бездефектного блока на образце $A$ в 5 раз больше соответствующего размера на образце $B$. Этот вывод согласуется с данными, полученными другими методами.

Спектры КРC $\mathrm{AlN} / \mathrm{Si}(111)$ для структур $A$ и $B$ после синтеза методом MOCVD были подобны известным спектрам AlN, что обеспечивало надежную идентификацию наблюдавшихся пиков: $E_{2}($ high $)-651.3 \mathrm{~cm}^{-1}$, $A_{1}(\mathrm{TO})-619.3 \mathrm{~cm}^{-1}, A_{1}(\mathrm{LO})-885.6 \mathrm{~cm}^{-1}$.

После синтеза толстого верхнего слоя методом НVPE спектры КРС структур $\mathrm{AlN} / \mathrm{Si}(111)$ имели для структур $A$ и $B$ соответственно следующие пики: $E_{2}(h i g h)-655.0$ 
и $653.5 \mathrm{~cm}^{-1}, A_{1}(\mathrm{TO})-611.6$ и $617.0 \mathrm{~cm}^{-1}, A_{1}(\mathrm{LO})-$ 888.3 и $888.7 \mathrm{~cm}^{-1}$ (рис. 2).

Оптические изображения поверхности AlN после синтеза методом HVPE не выявили системы трещин.

Известно, что зарождение и размножение дислокаций в кристаллах происходят при деформациях, превышающих критические. Для большинства гетероструктур, как правило, считается, что термические деформации, по крайней мере при температурах меньше половины температуры плавления вещества, практически не релаксируют и проявляются в виде упругой деформации при комнатной температуре [3].

При температуре эпитаксии из-за различия постоянных решетки AlN и $\mathrm{Si}$ возникают растягивающие деформации в слое AlN, и с ростом толщины могут образовываться трещины (рис. 1). При этом чем больше толщина слоя по отношению к критической толщине, при которой происходит возникновение трещин, тем гуще образуются трещины [13]. Синтез слоя AlN методом MOCVD на подложке со слоем AIN, синтезированным методом RMS, и непосредственно на подложке $\mathrm{Si}(111)$ происходит в условиях разных критических толщин, при которых возникает пластическая деформация слоев: первый слой AlN часть упругих деформаций берет на себя. Это приводит к меньшей плотности трещин в слое AlN при MOCVD-синтезе. Последующее охлаждение до комнатной температуры и нагрев до температуры эпитаксии методом HVPE приводит к снятию упругой деформации структуры, поскольку в методе НVPE рост слоя AlN проходит по трехмерному механизму, что способствует снятию упругой деформации структуры, но ведет к увеличению величины $\omega_{\theta}$. Положение максимума пика $E_{2}($ high $)-655.0 \mathrm{~cm}^{-1}-$ показывает снижение деформации структуры типа $A$ по сравнению с деформацией для типа $B$ и незначительное отклонение пика от известных данных для ненапряженного AlN: $E_{2}(h i g h)-$ 655.5 [14] и $657.0 \mathrm{~cm}^{-1}$ [15].

Таким образом, формирование низкотемпературного слоя методом RMS и комбинированная газофазная эпитаксия слоев последовательно методами MOCVD и HVPE обеспечивает существенное снижение деформации слоя AlN на подложке $\mathrm{Si}(111)$ и подавление формирования трещин в слое.

\section{Благодарности}

Авторы благодарят компанию ООО „Квантовый кремний“ (Москва, Россия) за предоставление темплейтов $\operatorname{AlN} / \mathrm{Si}(111)$, а также В.К. Смирнова за полезные дискуссии.

\section{Финансирование работы}

Исследования В.Н. Бессолова, Е.В. Коненковой, В.Н. Пантелеева выполнены при финансовой поддержке Российского фонда фундаментальных исследований в рамках научного проекта № 20-08-00096.

\section{Конфликт интересов}

Авторы заявляют, что у них нет конфликта интересов.

\section{Список литературы}

[1] Feng Y., Wei H., Yang S., Zhang H., Kong S., Zhao G., Liu X. // CrystEngComm. 2014. V. 16. N 32. P. 7525-7528.

[2] Tanaka S., Honda Y., Kameshiro N., Iwasaki R., Sawaki N., Tanji T., Ichihahi M. // J. Cryst. Growth. 2004. V. 260. N 3-4. P. 360-365.

[3] Бессолов В.Н., Давыдов В.Ю., Жиляев Ю.В., Коненкова Е.В., Мосина Г.Н., Раевский С.Д., Родин С.Н., Шарофидинов Ш., Щеглов М.П., Seok P.H., Masayoshi K. // Письма в ЖТФ. 2005. Т. 31. В. 21. С. 30-39.

[4] Tamariz S., Martin D., Grandjean N. // J. Cryst. Growth. 2017. V. 476. P. 58-63.

[5] Bourret A., Barski A., Rouviere J.L., Renaud G., Barbier A. // J. Appl. Phys. 1998. V. 83. N 4. P. 2003-2009.

[6] Selvaduray G., Sheet L. // Mater. Sci. Technol. 1996. V. 9. N 6. P. 463-473.

[7] Mastro M.A., Eddy C.R., Jr., Gaskill D.K., Bassim N.D., Casey J., Rosenberg A., Holm R.T., Henry R.L., Twigg M.E. // J. Cryst. Growth. 2006. V. 287. N 2. P. 610-614.

[8] Jamil M., Grandusky J.R., Jindal V., Tripathi N., Shahedipour-Sandvik F. // J. Appl. Phys. 2007. V. 102. N 2. P. 023701.

[9] Liu H.Y., Tang G.S., Zeng F., Pan F. // J. Cryst. Growth. 2013. V. 363. P. $80-85$.

[10] Yamada T., Tanikawa T., Honda Y., Yamaguchi M., Amano H. // Jpn. J. Appl. Phys. 2013. V. 52. N 8S. P. 08JB16.

[11] Бессолов В.Н., Компан М.Е., Коненкова Е.В., Пантелеев В.Н., Родин С.Н., Щеглов М.П. // Письма в ЖТФ. 2019. T. 45. B. 11. C. 3-5.

[12] Бессолов В.Н., Компан М.Е., Коненкова Е.В., Пантелеев В.Н. // Письма в ЖТФ. 2020. Т. 46. В. 2. С. 12-14.

[13] Etzkorn E.V., Clarke D.R. // J. Appl. Phys. 2001. V. 89. N 2. P. 1025-1034.

[14] Goni A.R., Siegle H., Syassen K., Thomsen C., Wagner J.M. // Phys. Rev. B. 2001. V. 64. N 3. P. 035205.

[15] Zheng W., Zheng R., Huang F., Wu H., Li F. // Photon. Res. 2015. V. 3. N 2. P. $38-43$. 